\title{
Association between the proportion of sampled transition cows with increased nonesterified fatty acids and $\beta$-hydroxybutyrate and disease incidence, pregnancy rate, and milk production at the herd level
}

\author{
P. A. Ospina, ${ }^{*}$ D. V. Nydam,$\dagger^{1}$ T. Stokol, $\dagger$ and T. R. Overton* \\ *Department of Animal Science, College of Agriculture and Life Sciences, Cornell University, Ithaca, NY 14853 \\ †Department of Population Medicine and Diagnostic Sciences, College of Veterinary Medicine, Cornell University, Ithaca, NY 14853
}

\section{ABSTRACT}

In this study the herd alarm level was defined as the proportion of sampled transition cows per herd with increased prepartum nonesterified fatty acid (NEFA), postpartum $\beta$-hydroxybutyrate (BHBA), or NEFA concentrations that were associated with herd-level incidence of displaced abomasum (DA) or clinical ketosis (CK), pregnancy rate (PR), and milk production. The objectives were to 1 ) identify the herd alarm level for excessive negative energy balance and 2) describe the herd-level prevalence of this proportion. This was a prospective cohort study of 60 free-stall herds fed total mixed rations in the northeast United States. Two cohorts of approximately 15 animals were assessed for prepartum NEFA and postpartum BHBA and NEFA. The herd alarm level (i.e., the proportion of sampled animals above a certain metabolite threshold) was as follows: $15 \%$ had prepartum NEFA of $0.27 \mathrm{mEq} / \mathrm{L} ; 15$ and $20 \%$ had BHBA of 10 and $12 \mathrm{mg} / \mathrm{dL}$, respectively; and $15 \%$ had postpartum NEFA of 0.60 and $0.70 \mathrm{mEq} / \mathrm{L}$. The different herd alarm levels correspond to differences between the metabolites and respective herd-level effect. The herd-level effects for herds above the herd alarm level for prepartum NEFA were $3.6 \%$ increase in $\mathrm{DA}$ and CK incidence, $1.2 \%$ decrease in PR, and $282 \mathrm{~kg}$ decrease in average mature equivalent 305-d (ME 305) milk. For BHBA, the herd-level effects were a $1.8 \%$ increase in DA and CK, $0.8 \%$ decrease in PR, and 534 and $358 \mathrm{~kg}$ decrease in projected ME 305 milk yield for heifers and cows, respectively. For postpartum NEFA, the herd-level effects were $1.7 \%$ increase in DA and CK, $0.9 \%$ decrease in PR, and 288 and $593 \mathrm{~kg}$ decrease in projected ME 305 milk yield for heifers and cows, respectively. The prevalence of herds in which more than $15 \%$ of animals sampled had prepartum NEFA concentration $\geq 0.30 \mathrm{mEq} / \mathrm{L}$ was $75 \%$, BHBA $\geq 12 \mathrm{mg} /$ $\mathrm{dL}$ was $40 \%$, and postpartum NEFA $\geq 0.70 \mathrm{mEq} / \mathrm{L}$ was

Received January 11, 2010.

Accepted April 30, 2010.

${ }^{1}$ Corresponding author: dvn2@cornell.edu
$65 \%$. This study showed that there were detrimental herd-level effects if a large enough proportion of cows had increased metabolite concentrations, and further demonstrated that a high prevalence of herds have opportunity for improvement.

Key words: herd alarm level, nonesterified fatty acid, $\beta$-hydroxybutyrate

\section{INTRODUCTION}

The transition from late gestation to early lactation is a critical period in a dairy cow's life because failure to successfully overcome the negative energy balance (NEB) caused by the sudden increase in energy demand attributed to lactation and lagging DMI (Drackley et al., 2001) can increase the risk of detrimental health and reproductive outcomes (Herdt, 2000). At the cow level, increased BHBA and NEFA concentrations have been used as markers of excessive NEB. Previous studies have shown that increased concentrations of these metabolites are associated with increased risk of developing detrimental health (Cameron et al., 1998; LeBlanc et al., 2005; Ospina et al., 2010a), reproductive (Walsh et al., 2007; Ospina et al., 2010b), and production outcomes (Dohoo and Martin, 1984; Duffield et al., 2009).

Recently, objective cow-level thresholds have been determined for increased BHBA and NEFA concentrations that are associated with disease, and reproduction, and production outcomes (LeBlanc et al., 2005; Duffield et al., 2009; Ospina et al., 2010a). This information allows the identification of individual cows at risk for these downstream outcomes based on their NEB status during the transition period. However, despite all of the NEB information available at the cow level and its association with downstream outcomes, individual cow strategies for prevention of subclinical disease are still a challenge (Duffield, 2000). This is in part because changes associated with NEB adaptation can start as early as 6 wk prepartum (Drackley et al., 2001). Efforts to improve NEB status should be implemented at the herd level, where decisions about nutritional manage- 
ment and other aspects of the environment and herd management that in turn affect pre- and postpartum groups of cattle can be addressed appropriately.

Unfortunately, information regarding the appropriate herd alarm levels (i.e., the proportion of sampled animals with increased concentrations of NEFA and BHBA) have not been well defined (Oetzel, 2004). The objectives of this study were to 1) identify the herd alarm level for excessive NEB (i.e., the proportion of sampled animals with increased NEFA and BHBA) that was associated with herd-level changes in incidence of displaced abomasum (DA) and clinical ketosis (CK), 21-d pregnancy rate (PR), and projected mature equivalent 305-d (ME 305) milk and 2) describe the distribution of the herd-level prevalence of this proportion among herds enrolled in this study.

\section{MATERIALS AND METHODS}

\section{Study Population and Study Design}

A prospective cohort study was conducted from a convenience sample of dairy herds in New York, Pennsylvania, and Vermont between January 2006 and July 2007; further details of this study can be found in Ospina et al. (2010a). To be included in this study a herd must have 1) had >250 milking cows, 2) had free-stall housing, 3) fed a TMR-based diet, 4) participated in DHIA or used Dairy Comp 305 (version 2009, Valley Ag Software, Tulare, CA) or both, and 5) had follow-up information on at least 10 animals from each cohort.

In each herd, 2 separate cohorts of approximately 15 healthy transition animals were sampled cross-sectionally. To reflect common herd demographics, one-third of the animals sampled were primiparous. Animals 14 to $2 \mathrm{~d}$ prepartum were selected to form the prepartum cohort and animals 3 to $14 \mathrm{~d}$ postpartum were selected to form the postpartum cohort. Healthy was defined as not being in the sick pen, not currently receiving any medical treatment, and not displaying sick cow signs based on the interpretation of the research staff. This cross-sectional sampling scheme was done to estimate the herd-level prevalence of animals with an increased NEFA or BHBA concentration with $90 \%$ confidence. Ten milliliters of blood was collected from each animal's coccygeal vessel with a plain red-top evacuated tube. The samples were handled according to recommendations by Stokol and Nydam (2005).

All samples were analyzed using an automated wet chemistry analyzer (Hitachi 917, Roche Diagnostics, Indianapolis, IN) at the Cornell University Animal Health Diagnostic Center (Ithaca, NY). The sera from the prepartum cohort were analyzed for NEFA (NEFAC, Wako Chemicals USA Inc., Richmond, VA) and hemolysis and the sera from the postpartum cohort were analyzed for NEFA, BHBA ( $\beta$-HB, Catachem Inc., Bridgeport, $\mathrm{CT}$ ), and hemolysis (Stokol and $\mathrm{Ny}-$ dam, 2006). Hemolyzed samples were excluded from the analysis.

Three outcomes of interest were evaluated: incidence of DA or CK in sampled animals, herd PR, and the average ME 305 milk production from sampled animals. Cases of DA or CK within 30 DIM were recorded and, for consistency of documentation, disease and case definitions were provided to farm personnel as in Ospina et al. (2010b). Briefly, DA was defined as movement of the fourth compartment of the stomach to a location on the right or left side of the cow and detected by auscultating a "ping" sound with finger percussion. Often, this cow had an abrupt decrease in milk production and was off feed. Clinical ketosis was defined as a cow that was off feed and had sudden weight loss and decreased milk production but had no other detectable signs of disease and was treated with dextrose, propylene glycol, or steroids, or all 3 (Duffield et al., 1999). The average $\mathrm{PR}$ of the two 21-d periods after the individual farm voluntary waiting period was recorded from Dairy Comp 305 to evaluate early-lactation herd reproductive performance. Pregnancy diagnosis was performed by the herd veterinarian by either manual palpation or ultrasound per rectum. At approximately 120 DIM, ME 305 milk yield was measured (incorporating 4 test days) and retrieved from DHIA or on-farm Dairy Comp 305 records.

\section{Statistical Analysis}

In summary, the prepartum and postpartum cohorts were analyzed separately; however, for both cohorts 3 models with 3 continuous outcomes were analyzed. The 3 outcomes were 1) incidence of DA or CK or both, 2) herd PR, and 3) ME 305 milk. The outcomes were reported as the relative change between herds below or above the herd alarm level. Herd size was divided by 100 so that a 1-unit change in the model was reflective of a change in herd size of 100 animals. Cows and heifers were grouped in the final analyses if the association between the metabolites and the outcome of interest were similar between the 2 groups. All statistical analyses were performed using SAS (version 9.1, SAS Institute Inc., Cary, NC) and evaluated with a mixed effects models (PROC MIXED) with herd as a random effect.

All outcomes of interest (incidence of DA or CK, herd PR, and ME 305 milk yield) were analyzed as continuous outcomes. Although pregnancy at the individual cow level represents a dichotomous outcome, the herd PR can be evaluated as a continuous outcome. 
At the herd level, PR is represented with a binomial distribution that can be approximated to the normal distribution when the sample size is large (Casella and Berger, 1990). By approximating the binomial distribution to the normal, herd-level PR can be evaluated as a continuous outcome. In addition, to ensure that the cohorts of animals sampled in the transition period were represented in the $\mathrm{PR}$, the animals were followed forward in time and the average of two 21-d periods post individual herd voluntary waiting period were used.

Metabolite Thresholds and Proportion of Sampled Animals. The herd-alarm level consists of 2 numbers: 1) the metabolite (NEFA or BHBA) concentration threshold above which detrimental downstream outcomes are most likely to occur and 2) the proportion of animals with metabolite concentrations above this threshold that is associated with herd-level downstream outcomes. To establish the herd alarm level, both of these parameters were evaluated concurrently. The lowest metabolite concentration and smallest proportion that yielded the smallest chance of committing a type I error and had the largest change in the outcome of interest (e.g., largest increase in disease incidence) was kept in the final model.

The metabolite concentrations were evaluated within the range identified as critical thresholds associated with individual cow health effects by previous reports (Duffield et al., 2009; Ospina et al., 2010a). According to these reports, the metabolite ranges were as follows: prepartum NEFA, 0.27 to $0.37 \mathrm{mEq} / \mathrm{L}$; postpartum NEFA, 0.36 to $0.72 \mathrm{mEq} / \mathrm{L}$; and BHBA, 7 to $14 \mathrm{mg} / \mathrm{dL}$.

Within each herd, the proportion of animals above the thresholds was determined and $25 \%$ was evaluated as the initial proportion. To increase the sensitivity of the herd alarm level, the proportion of animals with increased metabolite levels was lowered by $5 \%$ increments until the highest estimate and lowest $P$-value were determined, similar to the approach taken in Duffield et al. (2009).

Prevalence. To identify the prevalence of herds above the herd alarm levels most commonly associated with downstream outcomes, herds in which more than $15 \%$ of sampled animals had increased prepartum NEFA concentrations $\geq 0.30 \mathrm{mEq} / \mathrm{L}, \mathrm{BHBA} \geq 12 \mathrm{mg} /$ $\mathrm{dL}$, and postpartum NEFA $\geq 0.70 \mathrm{mEq} / \mathrm{L}$ were counted. Bar charts with 4 categories $(\leq 15,>15$ to $\leq 25,>25$ to $\leq 35$, and $>35$ ) for the proportion of animals with metabolites above the thresholds were created.

\section{RESULTS}

\section{Descriptive Data}

Sixty herds met the inclusion criteria, and from these herds 1,672 cows were included in the analysis. There were 867 animals in the prepartum cohort (37\% heifers and $63 \%$ cows) and 805 in the postpartum cohort $(41 \%$ heifers and $59 \%$ cows). The number of milking cows per herd ranged from 353 to 2,770 , with a mean of 950 . The animals sampled had a mean incidence of DA or CK or both of $8.3 \%$, an average herd PR of $19.7 \%$, and an average ME 305 milk of 12,487 kg.

\section{Multivariable Analysis}

Prepartum Cohort NEFA. The herd alarm level for all outcomes (DA or CK, PR, and ME 305 milk) was defined as more than $15 \%$ of animals sampled having prepartum NEFA $\geq 0.27 \mathrm{mEq} / \mathrm{L}$ (Table 1). Heifers and cows were grouped in the analysis for all outcomes of interest because the results between the groups were similar. Herds above this alarm level (i.e., when more than $15 \%$ of the sampled animals had a prepartum NEFA concentration $\geq 0.27 \mathrm{mEq} / \mathrm{L}$ ) had a $3.6 \%$ increase in the incidence of DA or CK or both $(P$ $=0.006)$, a $1.2 \%$ decrease in PR $(P=0.006)$, and a 285 $\mathrm{kg}$ decrease in ME 305 milk yield $(P=0.002)$. Herd size was a significant covariate in the $\mathrm{PR}$ and milk production model $(P<0.0001)$ but was not significant in the disease model $(P=0.1)$. Results indicate that for each additional 100 cows on a farm, PR and ME 305 milk production decreased by $0.3 \%$ and $47 \mathrm{~kg}$, respectively.

Postpartum Cohort BHBA. Table 2 describes the herd alarm levels associated with postpartum BHBA concentrations and the outcomes of interest. The herd alarm level for the incidence of DA or CK or both and PR was defined as more than $15 \%$ of sampled animals having BHBA $\geq 12 \mathrm{mg} / \mathrm{dL}$. Herds above the alarm level (i.e., when more than $15 \%$ of the sampled animals had a BHBA concentration $\geq 12 \mathrm{mg} / \mathrm{dL}$ ) had a $1.8 \%$ increase in the incidence of DA or CK or both $(P=0.03)$ and a $0.8 \%$ decrease in PR $(P=0.03)$. The results for ME 305 milk were stratified by parity because the herd alarm level between heifers and cows was different. The ME 305 milk yield herd alarm level for heifers $(\mathrm{n}=335)$ was defined as more than $20 \%$ of sampled heifers having BHBA $\geq 12 \mathrm{mg} / \mathrm{dL}$, and the herd alarm level for cows ( $\mathrm{n}=470)$ was defined as more than $15 \%$ of sampled cows having BHBA $\geq 10 \mathrm{mg} / \mathrm{dL}$. Heifers in herds above the alarm level had a 534-kg decrease in ME 305 milk yield $(P=0.0002)$, and cows in herds above the alarm level had a $358-\mathrm{kg}$ decrease in ME 305 milk yield $(P$ $=0.0004)$. Herd size was a significant predictor $(P<$ 0.0001) of all outcomes except the incidence of DA or CK or both $(P=0.8)$. Results indicate that for each additional 100 cows on a farm, PR and average ME 305 milk production decreased.

Postpartum Cohort NEFA. Table 3 describes the herd alarm levels associated with postpartum NEFA 
Table 1. Herd-level effect of increased prepartum NEFA concentrations on disease, pregnancy rate, and mature equivalent 305-d (ME 305) milk

\begin{tabular}{lccc}
\hline Effect and covariate & Change & SE & $P$-value \\
\hline I. Effect on disease $^{1}$ & In percentage of disease & & \\
Herd alarm level $^{2}$ & 3.6 & 1.3 & 0.006 \\
Herd size $^{2}$ & -0.2 & 0.1 & 0.1 \\
II. Effect on pregnancy rate & & \\
Herd alarm level $_{\text {Herd size }}^{2}$ & In pregnancy rate (\%) & 0.4 & 0.006 \\
III. Effect on average ME 305 milk $^{4}$ & -1.2 & 0.04 & $<0.0001$ \\
Herd alarm level & -0.3 & & \\
Herd size $^{2}$ & In ME 305 milk (kg) & 91 & 0.002 \\
\hline
\end{tabular}

${ }^{1}$ Effect on disease if more than $15 \%$ of animals sampled had NEFA concentration $>0.27 \mathrm{mEq} / \mathrm{L}$. Disease is measured as the proportion of sampled animals that developed a displaced abomasum or clinical ketosis or both.

${ }^{2}$ Herd size: 1 unit change $=100$ additional cows.

${ }^{3}$ Effect on pregnancy rate if more than $15 \%$ of animals sampled had NEFA concentration $\geq 0.27 \mathrm{mEq} / \mathrm{L}$. Herd pregnancy rate is measured as the average of the two 21-d periods post herd voluntary waiting period.

${ }^{4}$ Effect on average ME 305 milk if more than $15 \%$ of animals sampled had prepartum NEFA concentration $\geq 0.27 \mathrm{mEq} / \mathrm{L}$.

concentrations and the outcomes of interest. The herd alarm level for the incidence of DA or CK or both was defined as more than $15 \%$ of sampled animals having postpartum NEFA concentrations $\geq 0.70 \mathrm{mEq} / \mathrm{L}$. Herds above this alarm level had a $1.7 \%$ increase in incidence of DA or CK or both $(P=0.04)$. The herd alarm level for the PR was defined as more than $15 \%$ of animals having NEFA concentrations $\geq 0.60 \mathrm{mEq} / \mathrm{L}(P=0.05)$. Herds above this alarm level had a $0.9 \%$ decrease in PR. The results for ME 305 milk were stratified by

Table 2. Herd-level effect of increased BHBA concentrations on disease, pregnancy rate, and mature equivalent 305-d (ME 305) milk

\begin{tabular}{|c|c|c|c|}
\hline Effect and covariate & Change & SE & $P$-value \\
\hline & In percentage of disease & & \\
\hline \multicolumn{4}{|l|}{ I. Effect on disease ${ }^{1}$} \\
\hline Herd alarm level & 1.8 & 0.8 & 0.03 \\
\hline Herd $\operatorname{size}^{2}$ & 0.02 & 0.08 & 0.8 \\
\hline & In pregnancy rate $(\%)$ & & \\
\hline \multicolumn{4}{|c|}{ II. Effect on herd pregnancy rate ${ }^{3}$} \\
\hline Herd alarm level & -0.8 & 0.4 & 0.03 \\
\hline Herd size 2 & -0.3 & 0.04 & $<0.0001$ \\
\hline \multicolumn{4}{|c|}{ III. Effect on average ME 305 milk in heifers ${ }^{4}$} \\
\hline Herd alarm level & -534 & 141 & 0.0002 \\
\hline Herd size ${ }^{2}$ & -64 & 12 & $<0.0001$ \\
\hline \multirow{2}{*}{\multicolumn{4}{|c|}{ IV. Effect on average ME 305 milk in cows ${ }^{5}$}} \\
\hline & & & \\
\hline Herd alarm level & -358 & 99 & 0.0004 \\
\hline Herd size ${ }^{2}$ & -53 & 10 & $<0.0001$ \\
\hline
\end{tabular}

${ }^{1}$ Effect on disease if more than $15 \%$ of animals sampled postpartum had BHBA concentration $\geq 12 \mathrm{mg} / \mathrm{dL}$. Disease is measured as the proportion of sampled animals that developed displaced abomasum or clinical ketosis or both.

${ }^{2}$ Herd size: 1 unit change $=100$ additional cows.

${ }^{3}$ Effect on herd pregnancy rate if more than $15 \%$ of animals sampled postpartum had BHBA concentration $\geq 12$ $\mathrm{mg} / \mathrm{dL}$. Herd pregnancy rate is measured as the average of the two 21-d periods post herd voluntary waiting period.

${ }^{4}$ Effect on average ME 305 milk in heifers if more than $20 \%$ of heifers sampled postpartum had BHBA concentration $\geq 12 \mathrm{mg} / \mathrm{dL}$.

${ }^{5}$ Effect on average ME 305 milk in cows if more than $15 \%$ of cows sampled postpartum had BHBA concentration $\geq 10 \mathrm{mg} / \mathrm{dL}$ 


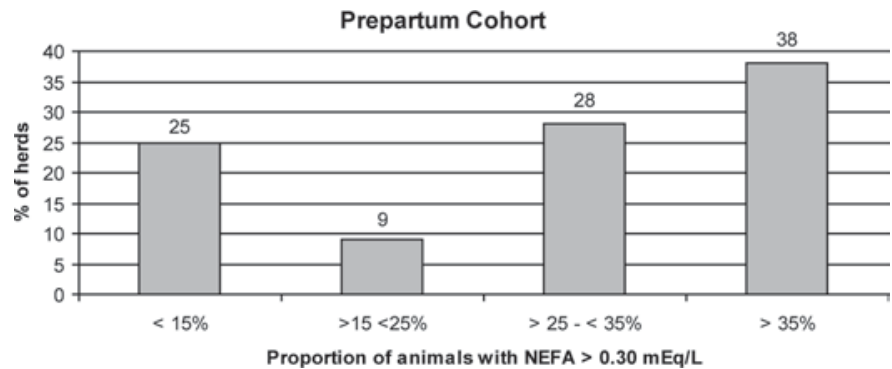

Figure 1. The prevalence of herds in which more than $15 \%$ of sampled animals had prepartum NEFA concentration $\geq 0.30 \mathrm{mEq} / \mathrm{L}$.

parity because the herd alarm level between heifers and cows was different. If more than $15 \%$ of the heifers (n $=335)$ sampled had postpartum NEFA $\geq 0.60 \mathrm{mEq} / \mathrm{L}$, then ME 305 decreased by $288 \mathrm{~kg}(P=0.07)$. If more than $15 \%$ of the cows $(n=470)$ sampled had postpartum NEFA concentrations $\geq 0.70 \mathrm{mEq} / \mathrm{L}$, then ME 305 decreased by $593 \mathrm{~kg}(P<0.0001)$. Herd size was included as a continuous covariate in all models and was significantly associated $(P<0.0001)$ with all outcomes except for DA or CK $(P=0.9)$. Results indicate that for each additional 100 cows on a farm, PR and average ME 305 milk production decreased.

Prevalence. From the 60 herds in the study, the prevalence of herds in which more than $15 \%$ of sampled

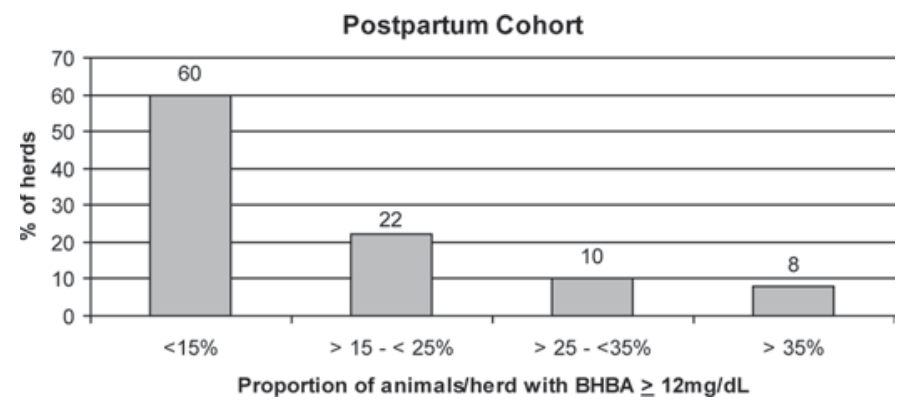

Figure 2. The prevalence of herds in which more than $15 \%$ of sampled animals had BHBA concentration $\geq 12 \mathrm{mg} / \mathrm{dL}$.

animals were above the metabolite threshold was as follows: $75 \%$ had prepartum NEFA $\geq 0.30 \mathrm{mEq} / \mathrm{L}, 40 \%$ had BHBA $\geq 12 \mathrm{mg} / \mathrm{dL}$, and $65 \%$ had postpartum NEFA $\geq 0.70 \mathrm{mEq} / \mathrm{L}$ (Figures 1, 2, and 3).

\section{DISCUSSION}

Several studies have investigated the association between individual transition animals with increased NEFA or BHBA concentrations and detrimental downstream outcomes (Cameron et al., 1998; Duffield et al., 2009; Ospina et al., 2010a). Based on empirical observation, $>10 \%$ has been suggested as a herd alarm level (i.e., the proportion of animals with increased NEFA

Table 3. Herd-level effect of increased postpartum NEFA concentrations on disease, pregnancy rate, and mature equivalent 305-d (ME 305) milk

\begin{tabular}{|c|c|c|c|}
\hline Effect and covariate & Change & $\mathrm{SE}$ & $P$-value \\
\hline & In percentage of disease & & \\
\hline \multicolumn{4}{|l|}{ I. Effect on disease ${ }^{1}$} \\
\hline Herd alarm level & 1.7 & 0.8 & 0.04 \\
\hline Herd size $^{2}$ & -0.003 & 0.07 & 0.9 \\
\hline & In pregnancy rate $(\%)$ & & \\
\hline $\begin{array}{l}\text { 11. Effect on herd pre } \\
\text { Herd alarm level }\end{array}$ & -09 & \multicolumn{2}{|c|}{ II. Effect on herd pregnancy rate ${ }^{3}$} \\
\hline Herd size $^{2}$ & -0.3 & 0.04 & $<0.0001$ \\
\hline \multicolumn{4}{|c|}{ III. Effect on average ME 305 milk in heifers ${ }^{4}$} \\
\hline Herd alarm level & -288 & 159 & 0.07 \\
\hline Herd size ${ }^{2}$ & -66 & 13 & $<0.0001$ \\
\hline \multicolumn{4}{|c|}{ IV. Effect on average ME 305 milk in cows ${ }^{5}$} \\
\hline Herd alarm level & -593 & 107 & $<0.0001$ \\
\hline Herd size $^{2}$ & -56 & 10 & $<0.0001$ \\
\hline
\end{tabular}

${ }^{1}$ Effect on disease if more than $15 \%$ of animals sampled had postpartum NEFA concentration $\geq 0.70 \mathrm{mEq} / \mathrm{L}$. Disease is measured as the proportion of sampled animals that developed displaced abomasum or clinical ketosis or both.

${ }^{2}$ Herd size: 1 unit change $=100$ additional cows.

${ }^{3}$ Effect on herd pregnancy rate if more than $15 \%$ of animals sampled had postpartum NEFA concentration $\geq 0.60 \mathrm{mEq} / \mathrm{L}$. Herd pregnancy rate is measured as the average of the two 21-d periods post herd voluntary waiting period.

${ }^{4}$ Effect on average ME 305 milk in heifers if more than $15 \%$ of heifers sampled postpartum had NEFA concentration $\geq 0.60 \mathrm{mEq} / \mathrm{L}$

${ }^{5}$ Effect on average ME 305 milk in cows if more than $15 \%$ of cows sampled postpartum had NEFA concentration $\geq 0.70 \mathrm{mEq} / \mathrm{L}$ 
or BHBA concentrations associated with detrimental downstream outcomes) but it has not been well defined (Oetzel, 2004). We evaluated the herd alarm level by first examining the effect of $\geq 25 \%$ of sampled animals being above the threshold and then reducing this proportion by $5 \%$ increments. Twenty-five percent was chosen as a conservative starting point because, based on the suggested $10 \%$ herd alarm level, this starting point would decrease the likelihood of misclassifying herds as false positives. The decreasing increments of $5 \%$ allowed us to examine cut-points with increasing sensitivity until the lowest cut-point with both an acceptable risk of a type I error and a meaningful magnitude of effect was found. The outcomes assessed here were incidence of DA or CK or both, PR, and ME 305 milk production. Generally, the results of this herd-level study were in agreement with previous individual cow studies: increased NEFA or BHBA were associated with detrimental health, reproduction, and milk production outcomes (Duffield et al., 2009; Ospina et al., 2010b).

The herd alarm level for excessive NEB [i.e., the proportion of sampled animals with increased metabolite (NEFA or BHBA) concentrations that were associated with herd-level outcomes] was $15 \%$, except when sampling heifers for BHBA with milk production as the outcome, where the proportion was $20 \%$. These were the smallest proportions that yielded the largest change in the outcome and the smallest chance of committing a type I error. The smallest proportion was chosen to increase the sensitivity of the test (i.e., minimize the false negatives). The herd alarm level for heifers may have been larger than it was for cows because of potential biological differences. Compared with cows, heifers have to balance maintenance and milk production as well as growth (Fox et al., 1999). As a result, heifers may be more capable of managing mobilized energy resources than cows and thus be more tolerant of increased BHBA concentrations before negative outcomes are measurable. Although Duffield et al. (2009) did not stratify by parity, he found that some cows produced more milk with higher BHBA concentrations.

Within each cohort, the thresholds for metabolite concentrations associated with the outcomes of interest were similar: $0.27 \mathrm{mEq} / \mathrm{L}$ for prepartum NEFA; 10 or $12 \mathrm{mg} / \mathrm{dL}$ for $\mathrm{BHBA}$, and 0.60 or $0.70 \mathrm{mEq} / \mathrm{L}$ for postpartum NEFA. The small difference in the BHBA concentration associated with effects on milk production is most likely attributable to a difference in sample size and population; cows and heifers were stratified in the analysis of milk production. The postpartum NEFA concentration was $0.60 \mathrm{mEq} / \mathrm{L}$ for both milk production in heifers and $\mathrm{PR}$ and $0.70 \mathrm{mEq} / \mathrm{L}$ for both milk production in cows and disease. The difference in NEFA concentration between heifers and cows in the milk

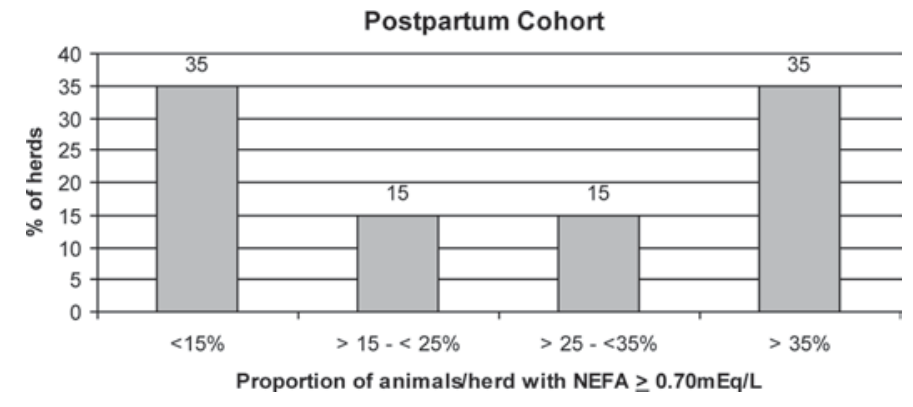

Figure 3. The prevalence of herds in which more than $15 \%$ of sampled animals had postpartum NEFA concentration $\geq 0.70 \mathrm{mEq} / \mathrm{L}$.

production model may be explained by the fact that these are different populations. In addition, the smaller sample size of heifers in the milk production model may make it difficult to see a smaller difference between the 2 groups (herds above the alarm level versus those that are not). Although the probability of saying that there is a difference in $\mathrm{PR}$ when there really is no difference is $5 \%$, a postpartum NEFA concentration of $0.60 \mathrm{mEq} / \mathrm{L}$ may reflect that the reproductive system may be more sensitive to increased NEFA concentrations in the transition period than the mechanism that increases the risk for a DA or CK.

To identify whether a herd is above the herd alarm level and at increased risk for negative downstream outcomes, the proportion of animals with increased NEFA or BHBA or both can be measured. For herd-level testing, a representative sample of adequate size is necessary. It is important to note that the desired confidence in the estimate of the proportion plays a larger role in sample size calculations than herd size. For example, to be $90 \%$ confident that the sample is representative of the herd, with an assumed prevalence of $15 \%$ of animals having increased metabolite concentrations, at least 15 animals at risk would need to be sampled. However, if 12 animals were sampled, in a herd with the same assumed prevalence the confidence that the sample is representative of the herd is reduced to $75 \%$.

One of the limitations of this study is that information on fewer than 15 animals was available in some herds. The implication of this is that the confidence that the sample represents the true herd-level prevalence is decreased. In addition, when evaluating the effects on milk production, the groups were stratified by parity because the herd alarm level for each group was different, further decreasing our sample size per herd. However, the herd alarm level for objective measures of poor adaptation to NEB still had a strong association with the outcomes of interest.

Herd size was also evaluated as a continuous covariate. The effect of increasing the herd size by 100 cows 
was significantly associated with PR and ME 305 milk production but not with DA or CK incidence. In Table 3, for example, after controlling for postpartum NEFA concentrations, the effect of increasing herd size by 100 cows did not significantly $(P=0.9)$ affect disease incidence, but for each additional 100 cows on a farm, PR decreased by $0.3(P<0.0001)$.

Although there has been considerable focus on the study of NEB in the transition period (Drackley, 1999), in high producing herds with good reproductive performance such as the ones studied here, 40 to $75 \%$ of herds were still above the herd alarm level for objective measures of poor adaptation of NEB. This demonstrates that several herds were below the herd alarm level and had better performance than those above; thus, there is still room for improvement in management of transition cows so as to minimize the effect of NEB. Recognizing herds at risk for increased disease incidence, decreased $\mathrm{PR}$, and decreased milk production based on the effects of increased NEFA or BHBA concentrations during the transition period may help farmers focus on improving herd energy balance. Farmers that choose to focus on herd-level factors for improving NEB at the individual cow level may do so by focusing on nutritional management, diet, comfort, social adaptation, and access to feed, which may be the best methods of minimizing the lagging DMI during the transition period, which is one of the major factors associated with NEB (Drackley et al., 2001).

\section{CONCLUSIONS}

The current study offers herd-level analysis of the transition period based on the identification of both the NEFA and BHBA concentration thresholds and the proportion of sampled animals with increased metabolite thresholds that would mostly likely result in detrimental herd-level outcomes. Compared with herds in which a low proportion of sampled animals had increased NEFA or BHBA concentrations, there was a higher incidence of DA and CK, lower PR, and decreased ME 305 milk production in herds in which a high proportion of sampled animals had increased metabolite concentrations. These herd-level effects were most likely to occur if metabolite concentration thresholds were $\geq 0.27 \mathrm{mEq} / \mathrm{L}$ for prepartum NEFA, $\geq 10$ or $12 \mathrm{mg} / \mathrm{dL}$ for postpartum BHBA, and 0.60 to $0.70 \mathrm{mEq} / \mathrm{L}$ for postpartum NEFA. The proportion of animals with NEFA or BHBA concentrations above the aforementioned thresholds that was associated with herd-level effects ranged from 15 to $20 \%$. These herd alarm levels may prove useful because in 40 to $75 \%$ of the herds sampled more than $15 \%$ of animals sampled had NEFA or BHBA concentrations above the thresholds.

\section{REFERENCES}

Cameron, R. E., P. B. Dyk, T. H. Herdt, J. B. Kaneene, R. Miller, H. F. Bucholtz, J. S. Liesman, M. J. Vandehaar, and R. S. Emery. 1998. Dry cow diet, management, and energy balance as risk factors for displaced abomasum in high producing dairy herds. J. Dairy Sci. 81:132-139.

Casella, G., and R. L. Berger. 1990. Statistical Inference. Duxbury Press, Belmont, CA.

Dohoo, I. R., and S. W. Martin. 1984. Subclinical ketosis: Prevalence and associations with production and disease. Can. J. Comp. Med. 48:1-5.

Drackley, J. K. 1999. ADSA foundation scholar award. Biology of dairy cows during the transition period: The final frontier? J. Dairy Sci. 82:2259-2273.

Drackley, J. K., T. R. Overton, and N. G. Douglas. 2001. Adaptations of glucose and long chain fatty acid metabolism in liver of dairy cows during the periparturient period. J. Dairy Sci. 84:E100E112.

Duffield, T. 2000. Subclinical ketosis in lactating dairy cattle. Vet. Clin. North Am. Food Anim. Pract. 16:231-253.

Duffield, T. F., K. E. Leslie, D. Sandals, K. Lissemore, B. W. McBride, J. H. Lumsden, P. Dick, and R. Bagg. 1999. Effect of a monensincontrolled release capsule on cow health and reproductive performance. J. Dairy Sci. 82:2377-2384.

Duffield, T. F., K. D. Lissemore, B. W. McBride, and K. E. Leslie. 2009. Impact of hyperketonemia in early lactation dairy cows on health and production. J. Dairy Sci. 92:571-580.

Fox, D. G., M. E. Van Amburgh, and T. P. Tylutki. 1999. Predicting requirements for growth, maturity, and body reserves in dairy. J. Dairy Sci. 82:1968-1977.

Herdt, T. H. 2000. Ruminant adaptation to negative energy balance. Influences on the etiology of ketosis and fatty liver. Vet. Clin. North Am. Food Anim. Pract. 16:215-230.

LeBlanc, S. J., K. E. Leslie, and T. F. Duffield. 2005. Metabolic predictors of displaced abomasum in dairy cattle. J. Dairy Sci. $88: 159-170$.

Oetzel, G. R. 2004. Monitoring and testing dairy herds for metabolic disease. Vet. Clin. North Am. Food Anim. Pract. 20:651-674.

Ospina, P. A., D. V. Nydam, T. Stokol, and T. R. Overton. 2010a. Evaluation of nonesterified fatty acids and $\beta$-hydroxybutyrate in transition dairy cattle in the northeast United States: Critical thresholds for prediction of clinical diseases. J. Dairy Sci. 93:546554.

Ospina, P. A., D. V. Nydam, T. Stokol, and T. R. Overton. 2010b. Associations of elevated nonesterified fatty acids and $\beta$-hydroxybutyrate concentrations with early lactation reproductive performance and milk production in transition dairy cattle in the northeastern United States. J. Dairy Sci. 93:1596-1603.

Stokol, T., and D. V. Nydam. 2005. Effect of anticoagulant and storage conditions on bovine nonesterified fatty acid and betahydroxybutyrate concentrations in blood. J. Dairy Sci. 88:31393144.

Stokol, T., and D. V. Nydam. 2006. Effect of hemolysis on nonesterified fatty acid and beta-hydroxybutyrate concentrations in bovine blood. J. Vet. Diagn. Invest. 18:466-469.

Walsh, R. B., J. S. Walton, D. F. Kelton, S. J. LeBlanc, K. E. Leslie, and T. F. Duffield. 2007. The effect of subclinical ketosis in early lactation on reproductive performance of postpartum dairy cows. J. Dairy Sci. 90:2788-2796. 